\title{
CONCENTRAÇÃO DO MERCADO INTERNACIONAL DE CELULOSE: PERSPECTIVAS PARA O BRASIL
}

\author{
Amarildo Hersen* \\ Romano Timofeiczyk Junior** \\ João Carlos Garzel Leodoro da Silva***
}

RESUMO: O objetivo deste trabalho consistiu em verificar a concentração do mercado internacional de celulose, no período de 2005 a 2014, e identificar o comportamento da participação relativa do Brasil na comercialização internacional de celulose. Os indicadores de concentração de mercado utilizados para a análise foram: razão de concentração - CR(4) e CR(8) - índice de Hirschmann-Herfindahl (HH), índice de Rosenbluth (B) e entropia (E). Os resultados sugerem baixa/moderada concentração de mercado, com tendência de redução, e aumento da participação do Brasil neste mercado. Ainda, as expectativas futuras são positivas para o setor no Brasil, devido aos fatores preço competitivo e expansão da oferta, com expectativa de ampliação da capacidade produtiva em mais de 6 milhões de toneladas/ano, até 2019.

PALAVRAS-CHAVE: Indústria florestal; Concentração de mercado; Celulose.

\section{CONCENTRATION OF THE INTERNATIONAL CELLULOSE MARKET: PERSPECTIVES FOR BRAZIL}

ABSTRACT: The concentration of the international cellulose market for 20052014 is verified and the behavior of Brazil's participation in the international cellulose trade is identified. Market concentration indexes for current analysis comprise concentration ratio - $\mathrm{CR}(4)$ and $\mathrm{CR}(8)$ - Hirschmann-Herfindahl index $(\mathrm{HH})$, Rosenbluth index (B) and entropy (E). Results suggest low/moderate market concentration, with a trend towards a decrease and increase in Brazil's participation in the market. Future perspectives in the sector for Brazil are finer, due to competitive prices and expansion, with an expansion of supply and the amplification of the production capacity with more than six million tons/years till 2019.

\footnotetext{
* Bolsista do CNPq. Doutorando em Economia e Política Florestal no Programa de Pós-Graduação em Engenharia Florestal da Universidade Federal do Paraná - UFPR, Curitiba, Brasil. E-mail: amarildohersen@yahoo.com.br

** Docente do Programa de Pós-Graduação em Engenharia Florestal da Universidade Federal do Paraná - UFPR, Curitiba, Brasil.

**** Docente do Programa de Pós-Graduação em Engenharia Florestal da Universidade Federal do Paraná - UFPR, Curitiba, Brasil.
} 
KEY WORDS: Forest industry; Market concentration; Cellulose.

\section{INTRODUÇÃO}

O setor florestal brasileiro, no ano de 2014, detinha mais de sete milhões de hectares de floresta plantada, com predominância de pinus e eucalipto. Neste mesmo ano, o segmento de celulose juntamente com o de papel alcançou a marca de 184.767 empregos formais, individualmente o valor da produção anual da celulose superou a casa dos R\$14,2 bilhões (SERVIÇO FLORESTAL BRASILEIRO, 2016).

No ano de 2013, de acordo com a IBÁ - Indústria Brasileira da Árvore (2015), a produção brasileira de celulose correspondeu a 15,13 milhões de toneladas e o volume direcionado para o mercado externo atingiu $62 \%$ do total produzido no país, mostrando que a indústria é significativamente voltada para o mercado externo. Já no ano de 2014, esse percentual mostrou-se ainda mais expressivo, subindo para 64\% do total produzido, de acordo com a IBÁ (INDÚSTRIA BRASILEIRA DA ÁRVORE, 2016). Desta forma, a variação da quantidade de celulose exportada de 2013 para 2014 foi de aproximadamente 1,2 milhões de toneladas, o que corresponde a um aumento absoluto de $12,65 \%$ no período.

Em se tratando de celulose de fibra longa, curta e pasta de alto rendimento, no ano de 2014 o Brasil produziu 16,46 milhões de toneladas de celulose, configurando-se como o quarto maior produtor mundial, posição alcançada desde o ano de 2008, perdendo apenas para EUA (57,42 milhões de toneladas), China (18,88 milhões de toneladas) e Canadá (17,29 milhões de toneladas). Já como produtor de celulose de eucalipto, o Brasil destaca-se na primeira posição (INDÚSTRIA BRASILEIRA DA ÁRVORE, 2016).

Em se tratando de mercado internacional, Valverde, Soares e Silva (2006) investigaram o desempenho das exportações brasileiras de celulose e para o período 1993-2002 o Brasil e demais países concorrentes tiveram como principal explicação para o crescimento das exportações o próprio crescimento do comércio mundial. Também neste estudo o Brasil apresentou o maior efeito de competitividade. Já Rocha e Soares (2014) analisaram o desempenho das exportações brasileiras de papel e celulose para o período 1997-2011 e concluíram que o crescimento do 
comércio mundial foi o principal fator que explicou o desempenho das exportações do setor para Estados Unidos, Canadá, Finlândia e Japão. A competitividade explicou o desempenho das exportações do setor de celulose e papel do Brasil e da China.

Considerando a indisponibilidade de estudos recentes e com viés voltado à participação de mercado, e considerando o importante destaque que algumas nações vêm apresentando, em termos de produção e comercialização, o problema da presente pesquisa é obter um panorama do comportamento do mercado internacional de celulose, nos últimos anos. O desempenho brasileiro extremamente positivo, notado no setor de celulose, tem como importante fator causal redefinições estratégicas de algumas indústrias, cujo foco tem sido o aumento do market-share, principalmente no mercado internacional. Desta forma, o objetivo deste trabalho foi verificar o que ocorreu em termos de concentração do mercado internacional de celulose, no período de 2005 a 2014, bem como identificar o comportamento da participação do Brasil na comercialização internacional.

\subsection{REFERENCIAL TEÓRICO}

A Escola de Chicago, representada nesta pesquisa por Stigler (1968) e Friedman (1984), defende a ideia de que uma concentração de mercado por si só não é um fator iníquo à sociedade capitalista, desde que nessa estrutura de mercado possam se verificar eficiência econômica e produção ao menor custo. "Estruturas concentradas, se resultarem em uma economia de recursos que compense seus efeitos anticompetitivos, não podem ser consideradas ineficientes" (GAMA; RUIZ, 2005, p. 2).

No entendimento de Stigler (1968), economias de escala não são consideradas como uma barreira à entrada, pois não impõem assimetria de custos entre as firmas estabelecidas e as firmas entrantes. Para o autor, só se pode identificar a ocorrência de barreiras à entrada na existência de assimetrias de custos entre as firmas instaladas e as firmas entrantes, isto é, quando há custos incorridos pelos entrantes, mas não pelas firmas estabelecidas. Desta forma, as empresas entrantes teriam que arcar com um prejuízo no qual as estabelecidas não arcaram quando entraram no mercado. 
A discussão sobre concentração de mercado e regulação de mercado, por intermédio do governo, mostra-se próxima e fortemente correlacionada para os autores da Escola de Chicago. Stigler (1968) questiona a regulação de mercado por parte do governo no sentido de entender a explicação de sua existência. A resposta de Stigler foi dada com a sua já clássica "Teoria da Captura" das agências governamentais. Para o autor, o processo regulatório seria controlado por grupos de interesse que através de restrições à concorrência, subsídios e fixação de preços obteriam benefícios para si em detrimento de consumidores e/ou contribuintes.

Para Friedman (1984), o objetivo do governo deve ser limitado. O autor salienta que sua principal função deve ser a de proteger nossa liberdade contra os inimigos externos e contra nossos próprios compatriotas; preservar a lei e a ordem; reforçar os contratos privados; promover mercados competitivos. Além desta função principal, o governo pode, algumas vezes, nos levar a fazer em conjunto o que seria mais difícil ou dispendioso fazer separadamente. Neste sentido, a preservação da liberdade é a principal razão para a limitação e descentralização do poder do governo.

$\mathrm{Na}$ verdade, precisa-se urgentemente, para a estabilidade e o crescimento econômico, de uma redução na intervenção do governo - e não de sua expansão. Tal redução ainda deixaria um papel importante para o governo nessas áreas. Convém que se use o governo para fornecer uma estrutura monetária estável à economia livre - isto é parte da função de propiciar uma estrutura legal estável. É também conveniente que o governo forneça uma estrutura geral econômica e legal que permita aos indivíduos fazer a economia crescer, se isto estiver de acordo com seus valores. As áreas mais importantes da política governamental que são relevantes para a estabilidade econômica estão constituídas pela política monetária e fiscal (FRIEDMAN, 1984).

O mercado livre também separa a eficiência econômica de outras características irrelevantes. O comprador de pão, por exemplo, não sabe a raça ou religião do agricultor que cultivou o trigo para fazer o pão. Consequentemente, o produtor de trigo está na posição de usar seus recursos tão efetivamente quanto possível, sejam quais forem as atitudes da comunidade com relação à raça ou religião. Além disso, há no mercado livre um incentivo econômico para separar a 
eficiência econômica de qualquer outra característica do indivíduo. Um homem de negócios ou empresário que expresse em sua atividade determinadas preferências, não relacionadas com a eficiência produtiva, ficará em posição de desvantagem comparativamente aos demais que não concordam com as referidas preferências. Desta forma o empresário se auto-impõe um preço mais elevado - diferente dos demais - resultando, em um mercado livre, na sua eliminação (FRIEDMAN, 1984).

\section{MATERIAL E MÉTODO}

Em termos de material de pesquisa, os dados de exportação de celulose aqui utilizados têm como origem o banco de dados estatísticos do United Nations Commodity Trade (COMTRADE, 2016). As referidas estatísticas apresentam-se anualizadas e correspondem ao período 2005-2014, uma vez que as estimativas para o ano de 2015 mostram-se ainda parciais, correndo-se o risco da realização de interpretações equivocadas caso este último exercício seja considerado na análise. Vale destacar que existe mais de vinte tipos diferentes de celulose, quando considerada a classificação de seis dígitos e sete quando considerada a classificação de quatro dígitos, conforme descrito na Quadro 1.

Quadro 1. Tipo de celulose e código conforme sistema harmonizado - quatro dígitos

\begin{tabular}{|c|c|}
\hline Código & Descrição \\
\hline 4701 & Pasta mecânica \\
\hline 4702 & Pasta química (para dissolução) \\
\hline 4703 & Pasta química (dissolvida a base de sulfato ou soda) \\
\hline 4704 & Pasta obtida (dissolvida a base de sulfito) \\
\hline 4705 & Pasta obtida a partir de papel (desperdícios e aparas) ou cartão ou outras matérias \\
\hline 4706 & fibrosas \\
\hline 4707 & Pasta obtida a partir de reciclados (desperdícios e resíduos) papel ou cartão \\
\hline
\end{tabular}

Fonte: COMTRADE (2016).

Para fins desta pesquisa, os valores foram agregados no código 47 (celulose), e os índices de concentração supracitados foram calculados tanto para quantidade física (Kg) quanto para valores monetários (US\$). 
Para mensurar a concentração do mercado internacional de celulose são utilizadas quatro medidas positivas ${ }^{4}$ : razão de concentração, índice de HirschmannHerfindahl, índice de Rosenbluth e entropia. A metodologia para o cálculo destas medidas está baseada em Resende (1994), Hoffmann (1998) e Kupfer; Hasenclever (2002). A utilização de várias medidas justifica-se pelo fato da teoria econômica não fornecer elementos conclusivos para uma escolha pontual entre os vários índices (BRAGA; MASCOLO, 1982).

Os indicadores de concentração são de uso comum pela comunidade científica internacional, tanto em outras áreas do conhecimento - Kazemzadeh; Zeinoddin (2015); Kalça; Ari (2013); Tushaj (2010); Rugayah (1993); - quanto na própria área de economia florestal - Lindblad; Schauerte; Flinkman (2016); Mateows; Amanuel; Asfaw (2015); Agricultural Technical Cooperation Working Group (2008); Li; Mccarthy; Urmanbetova (2004).

Também nacionalmente nota-se considerável utilização destes indicadores, como nos trabalhos de Almeida e Silva (2015); Ribeiro; Tonin (2010); Coelho Júnior et al. (2010); Coelho Júnior; Rezende; Oliveira (2013); Galvão et al. (2009); Noce et al. (2005); Silva (2003); Heimann; Dresch (2013).

Para a finalidade proposta, inicialmente é verificada a participação de cada país sobre o total de celulose comercializada internacionalmente no mundo, em cada um dos períodos, definida por:

$$
y_{i}=\frac{x_{i}}{q_{i}}
$$

Em que:

$y_{i}=$ participação do $i$-ésimo país no total de celulose comercializado internacionalmente;

$x_{i}=$ volume de celulose exportado pelo $i$-ésimo país;

$q_{i}=$ volume total de celulose comercializado internacionalmente.

4 Tem-se que medidas de concentração positivas não dependem de qualquer parâmetro comportamental, limitando-se ao nível e distribuição de parcelas de mercado. Diferentemente, as medidas normativas consideram também as preferências dos consumidores e interesses dos produtores, visando uma avaliação de cunho social (RESENDE; BOFF, 2002). 
Para o cálculo da razão de concentração, os valores de $y_{i}$ devem ser ordenados de maneira decrescente $\left(y_{1}>y_{2}>\ldots>y_{\mathrm{n}}\right)$.

A razão de concentração das $k$ maiores nações exportadoras é então dada por:

$$
C R_{k}=\sum_{i=1}^{k} y_{i}
$$

Para efeito deste trabalho, diante do grande número de países envolvidos na exportação de celulose, foram consideradas duas razões de concentração: $\mathrm{CR}(4)$ e $\mathrm{CR}(8)$.

Salienta-se, ainda, que as razões de concentração não levam em conta os dados da totalidade dos países exportadores, sendo consideradas medidas de concentração parciais. A omissão dos $(n-k)$ países dificulta o uso do $\mathrm{CR}_{k}$ como medida de poder de mercado (RESENDE; BOFF, 2002). Esta deficiência pode ser superada com a utilização de outras medidas, quais sejam: o índice de HirschmannHerfindahl (HH), índice de Rosenbluth (B) e entropia (E).

$\mathrm{O}$ índice de Hirschmann-Herfindahl (HH) é definido por:

$$
H H=\sum_{i=1}^{n} y_{i}^{2}
$$

Em que:

$$
\begin{aligned}
& n=\text { número total de países exportadores; } \\
& y_{i}{ }^{2}=\text { participação dos países no total ao quadrado. }
\end{aligned}
$$

Para o cálculo do índice de Rosenbluth (B) foi considerada também a ordenação decrescente de quantidade/valor exportados e sua grandeza identificada a partir de: 


$$
B=\frac{1}{2 \sum i y_{i}-1}
$$

O valor do índice de Hirschmann-Herfindahl, assim como o do índice de Rosenbluth, varia de $1 / n$ até 1 . Se $\mathrm{HH}=1 / n$, há indícios de uma divisão igualitária do mercado entre todos os países. Já quando $\mathrm{HH}=1$, tem-se a máxima concentração de mercado. Resende (1994) salienta que o índice de Hirschmann-Herfindahl corresponde à medida de concentração mais conveniente para comparações intertemporais.

Por fim, a entropia da distribuição, conforme Theil (1967), é definida por:

$$
E=\sum_{i=1}^{n} y_{i} \ln \frac{1}{y_{i}}
$$

O índice de entropia pode ser entendido como uma medida inversa de concentração (o valor máximo do índice corresponde a uma situação de concentração mínima), considerando que o valor da entropia varia de $\mathrm{E}=0$ (mercado composto por apenas um participante, ou seja, monopólico) até $\mathrm{E}=\log n$ (mercado composto por $n$ países com o mesmo volume/valor de exportação).

Com a finalidade de síntese, a interpretação de cada um dos indicadores está descrita na Tabela 2.

Tabela 2. Interpretação dos índices de concentração

\begin{tabular}{|c|c|c|c|c|c|c|c|c|}
\hline $\mathrm{HH}$ & Classificação & $\mathrm{CR}(4)$ & $\mathrm{CR}(8)$ & Classificação & B & Classificação & E & Classificação \\
\hline$=0$. & $\begin{array}{c}\text { tende a } \\
\text { concorrência } \\
\text { perfeita }\end{array}$ & $\mathrm{i}>0,75$ & $\mathrm{i}>0,90$ & $\begin{array}{l}\text { extremamen- } \\
\text { te concen- } \\
\text { trado }\end{array}$ & $\underset{1}{\stackrel{B}{\longrightarrow}}$ & $\begin{array}{l}\text { extremamen- } \\
\text { te concen- } \\
\text { trado }\end{array}$ & $\underset{0}{\mathrm{E} \rightarrow}$ & $\begin{array}{l}\text { extrema- } \\
\text { mente con- } \\
\text { centrado }\end{array}$ \\
\hline
\end{tabular}

(Continua) 
(Conclusão)

\begin{tabular}{|c|c|c|c|c|c|c|c|c|}
\hline $\mathrm{HH}$ & Classificação & $\mathrm{CR}(4)$ & $\mathrm{CR}(8)$ & Classificação & B & Classificação & $\mathrm{E}$ & Classificação \\
\hline$=1$. & monopólio & $\begin{array}{c}0,65< \\
\mathrm{i}<0,75\end{array}$ & $\begin{array}{c}0,85<\mathrm{i} \\
<0,90\end{array}$ & $\begin{array}{l}\text { alta concen- } \\
\text { tração }\end{array}$ & \multirow{2}{*}{$\underset{1 / n}{\rightarrow}$} & \multirow{2}{*}{$\begin{array}{l}\text { firmas com } \\
\text { igual parti- } \\
\text { cipação de } \\
\text { mercado }\end{array}$} & \multirow{2}{*}{$\begin{array}{c}\mathrm{E} \rightarrow \\
\log \\
n\end{array}$} & \multirow{2}{*}{$\begin{array}{c}\text { firmas com } \\
\text { igual parti- } \\
\text { cipação de } \\
\text { mercado }\end{array}$} \\
\hline$<0,1$ & $\begin{array}{l}\text { altamente } \\
\text { competitivo }\end{array}$ & $\begin{array}{c}0,50< \\
i<0,65\end{array}$ & $\begin{array}{c}0,70<\mathrm{i} \\
<0,85\end{array}$ & $\begin{array}{c}\text { concentração } \\
\text { moderada }\end{array}$ & & & & \\
\hline \multirow[t]{2}{*}{$>0,18$} & $\begin{array}{c}\text { altamente } \\
\text { concentrado }\end{array}$ & $\begin{array}{c}0,35< \\
i<0,50\end{array}$ & $\begin{array}{c}0,45<\mathrm{i} \\
<0,70\end{array}$ & $\begin{array}{c}\text { concentração } \\
\text { baixa }\end{array}$ & & & & \\
\hline & & $\mathrm{i}<0,35$ & $\mathrm{i}<0,45$ & $\begin{array}{l}\text { ausência de } \\
\text { concentração }\end{array}$ & & & & \\
\hline
\end{tabular}

Fonte: Adaptado de Moschandreas (2000), Medeiros e Ostroski (2006), Medeiros e Reis (1999), Silva (2003), Paula (2014).

De acordo com George, Joll e Lynk (1995) nenhum índice será sempre ideal, independentemente da situação, o aproveitamento de todos eles possibilita uma melhor utilização dos dados e, como consequência, resultados mais satisfatórios.

Os indicadores aqui expostos buscam identificar a existência de maior ou menor concentração do mercado em estudo. Com exceção do índice de entropia que configura-se como indicador de interpretação inversa - quanto mais próximo de zero se encontrar o indicador, menor a concentração de mercado e, contrariamente, quanto mais distante de zero maior a concentração de mercado.

Concluída a caracterização metodológica, a próxima seção apresenta os resultados e discussão da pesquisa.

\section{RESULTADOS E DISCUSSÃO}

Cabe destacar que um processo de concentração está estreitamente relacionado com o avanço da competitividade das empresas, que buscam estratégias com intuito de conquistar, ou no mínimo manter, sua posição no mercado.

Também, quando se fala de mercado internacional, deve-se considerar que cada nação é autônoma no uso de suas políticas macroeconômicas. No caso do Brasil se pode destacar, por exemplo, a política cambial com excessiva desvalorização, 
percebida a partir de 2012, como contributiva para melhor desempenho do setor no mercado internacional.

A média de países ofertantes de celulose no mercado internacional, na década analisada, foi de 127, com baixo desvio padrão, e caso hipoteticamente estes países comercializassem o mesmo volume do produto, a fatia de cada nação no mercado seria próximo de $0,8 \%$. Contudo, a realidade deste mercado mostra-se diferente.

Tabela 3. Participação dos 10 principais países exportadores de celulose no mercado internacional, ano 2014

\begin{tabular}{|c|c|c|c|c|c|c|c|c|}
\hline \multirow[b]{2}{*}{ Ranking } & \multicolumn{3}{|c|}{ Quantidade } & \multirow{2}{*}{$\begin{array}{c}\text { Preço } \\
\text { praticado } \\
\text { em relação } \\
\text { à média* }\end{array}$} & \multicolumn{3}{|c|}{ Valor } & \multirow{2}{*}{$\begin{array}{c}\text { Preço } \\
\text { praticado } \\
\text { em relação } \\
\text { à média* }\end{array}$} \\
\hline & País & $\%$ & $\begin{array}{c}\% \\
\text { Acumulado }\end{array}$ & & País & $\%$ & $\begin{array}{c}\% \\
\text { Acumulado }\end{array}$ & \\
\hline 1 & EUA & 23,6 & 23,6 & $\downarrow$ & EUA & 19,8 & 19,8 & \\
\hline 2 & Canadá & 10,5 & 34,1 & $\uparrow$ & Canadá & 14,9 & 34,7 & \\
\hline 3 & Brasil & 9,8 & 43,9 & $\uparrow$ & Brasil & 11,7 & 46,4 & \\
\hline 4 & Japão & 4,5 & 48,4 & $\downarrow$ & Chile & 6,4 & 52,8 & \\
\hline 5 & Chile & 4,2 & 52,5 & $\uparrow$ & Suécia & 6,0 & 58,8 & \\
\hline 6 & Reino Unido & 4,0 & 56,6 & $\downarrow$ & Finlândia & 4,7 & 63,5 & $\uparrow$ \\
\hline 7 & Suécia & 3,6 & 60,1 & $\uparrow$ & Indonésia & 3,8 & 67,3 & \\
\hline 8 & Alemanha & 3,5 & 63,6 & $\downarrow$ & Alemanha & 3,2 & 70,5 & \\
\hline 9 & Indonésia & 3,1 & 66,8 & $\uparrow$ & Rússia & 2,6 & 73,1 & $\uparrow$ \\
\hline 10 & Holanda & 3,1 & 69,8 & $\downarrow$ & Holanda & 2,4 & 75,6 & \\
\hline
\end{tabular}

Fonte: Dados da Pesquisa.

Nota: $\left({ }^{*}\right)$ Comportamento do preço praticado em relação à média dos preços da tonelada, ponderada pelo volume exportado.

Não diferente de toda a série histórica, no ano de 2014 os EUA foram responsáveis pelo maior volume comercializado no mercado internacional, seguido de Canadá e, na terceira posição, o Brasil. Os Estados Unidos, que correspondem ao CR(1), passaram de 24,2\%, no início do período analisado, para 23,6\%, em termos de quantidade exportada. Em se tratando de valor, os EUA detinham 20,5\% em 2005 passando para 19,8\% em 2014.

Contudo, ao confrontar os resultados referentes à quantidade e valor é 
possível perceber que a concentração é mais expressiva quando se trata de valor. Tal fato pode ser explicado pelo preço médio praticado no mercado, por países que dominam o mercado internacional de celulose. Ao ponderar a média de preço pelo volume exportado, é possível perceber que apenas os EUA, Reino Unido, Alemanha, Holanda e Japão vêm praticando preços médios de exportação abaixo da média de mercado, diferentemente dos demais países que lideram o ranking das exportações mundiais.

Confrontando-se a concentração do mercado pelas análises de valor e quantidade (Gráfico 1), nota-se que a análise referente a valor, agora na série histórica, evidencia maior concentração. Novamente o preço médio praticado por países que dominam o mercado é, na sua maioria, mais expressivo.
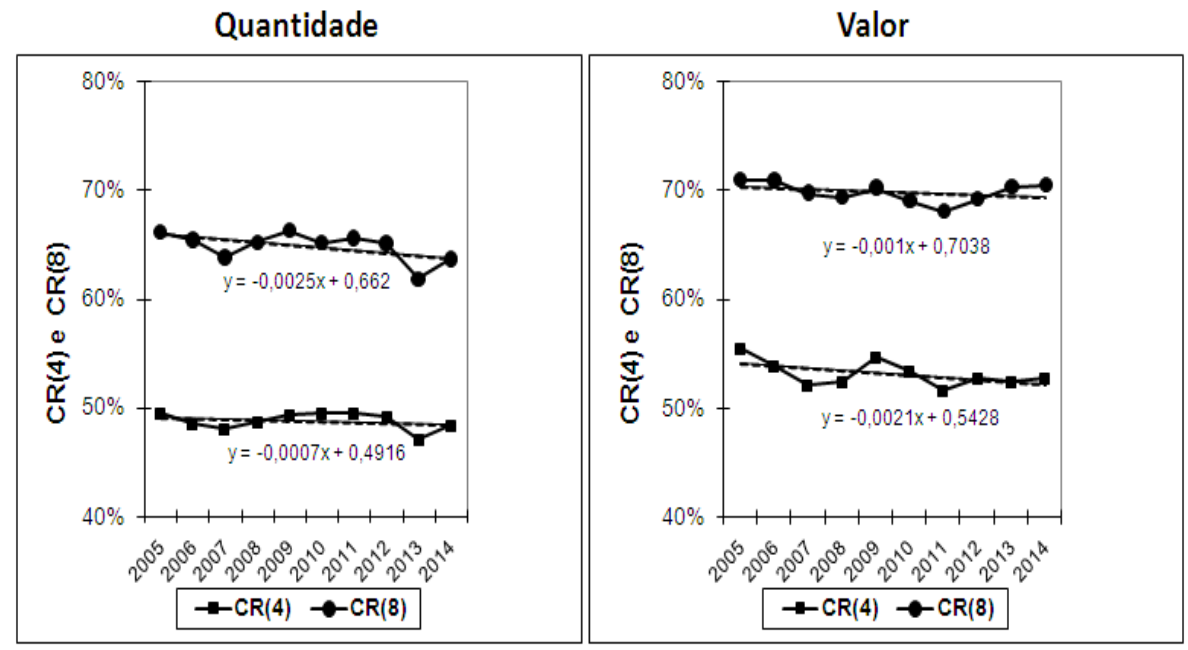

Gráfico 1. Evolução dos índices de concentração CR(4) e CR(8) do mercado internacional de celulose

De forma geral é possível notar tendência de queda na concentração do mercado em estudo, pelos indicadores $\mathrm{CR}(4)$ e $\mathrm{CR}(8)$, sob as óticas de quantidade e valor, queda esta evidenciada pela existência de coeficiente angular negativo nos modelos de tendência estimados.

Enquanto na análise de quantidade os países que ocupam as quatro primeiras posições do ranking de exportações concentram menos que $50 \%$ do total 
do mercado ao longo da série, na análise de valor se nota maior concentração onde os quatro países mais representativos no início da série concentravam cerca de 55\% do mercado, caindo para pouco menos de $53 \%$ no final da série. Considerandose os oito principais países representantes do mercado internacional $\mathrm{CR}(8)$, estes concentram na série histórica, em média, 65\% e 70\% na análise de quantidade e valor respectivamente.

Cumpre dizer que a posição dominante é definida quando, no caso, um país detém pelo menos $20 \%$ de participação no mercado, controlando, desta forma, boa parcela do mercado total (VIAN; LIMA; LIMA, 2006), e isto é possível de ser percebido no período. Contudo, a classificação dos indicadores $\operatorname{CR}(4)$ e $\operatorname{CR}(8)$ sugerem entre baixa e moderada concentração de mercado.

Com relação aos três outros indicadores calculados - índice de HirschmannHerfindahl, de Rosenbluth e Entropia - indicam, também, uma nítida diminuição da concentração ocorrida ao longo do período analisado (Gráfico 2).
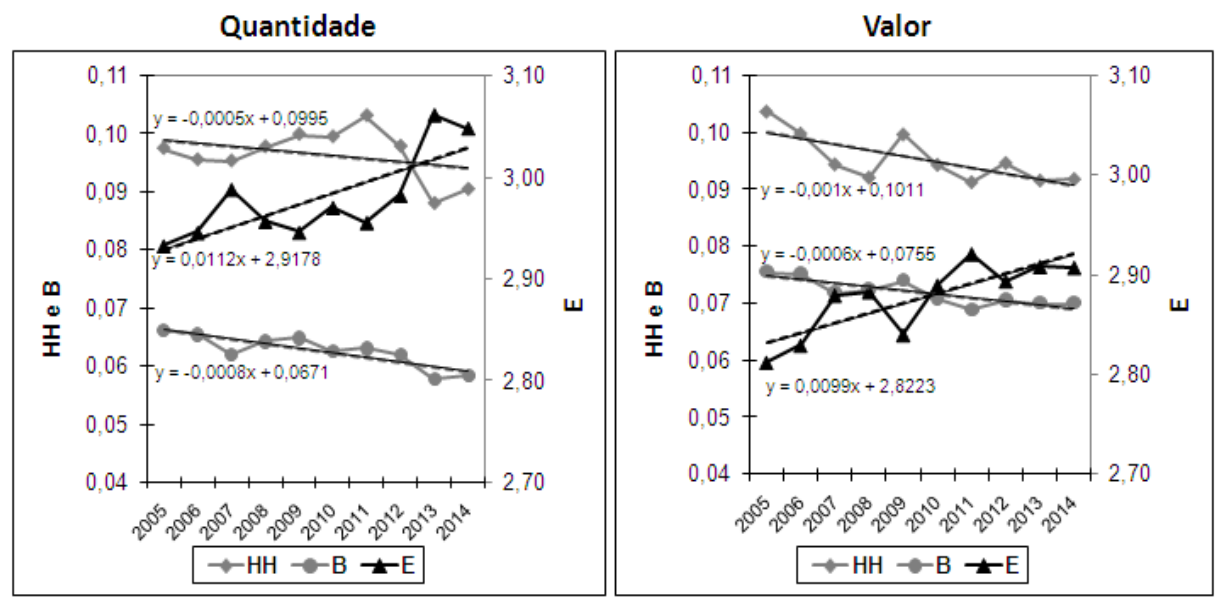

Gráfico 2. Índices de concentração HH, B e E do mercado internacional de celulose

Considerando os limites extremos, ou seja, de 2005 a 2014, para volume físico comercializado a diminuição no índice de Hirschmann-Herfindahl e de Rosenbluth foram de, respectivamente, 0,0070 e 0,0079, e o índice de entropia (que trata de uma medida inversa de concentração) teve uma variação positiva de 
0,1156. Já para a análise de valor monetário, a diminuição no índice de HirschmannHerfindahl e de Rosenbluth foram de, respectivamente, 0,0119 e 0,0055, e o índice de entropia teve uma variação positiva de 0,0945 .

Desta forma, a classificação do indicador HH sugere mercado altamente competitivo e B e E não extremamente concentrado. Também, de maneira unânime, independentemente da análise referente a volume físico ou valor, quando os indicadores são analisados na série histórica, sugerem tendência de queda da concentração do mercado sob análise, esta evidenciada pela existência de coeficiente angular negativo nos modelos de tendência estimados para os índices $\mathrm{HH}$ e B, bem como coeficiente angular positivo para o modelo de tendência estimado para o índice inverso $(\mathrm{E})$.

Apesar da tendência de desconcentração do mercado internacional de celulose, o Brasil - de forma contrária à tendência do mercado - vem aumentando sua participação (Gráfico 3).
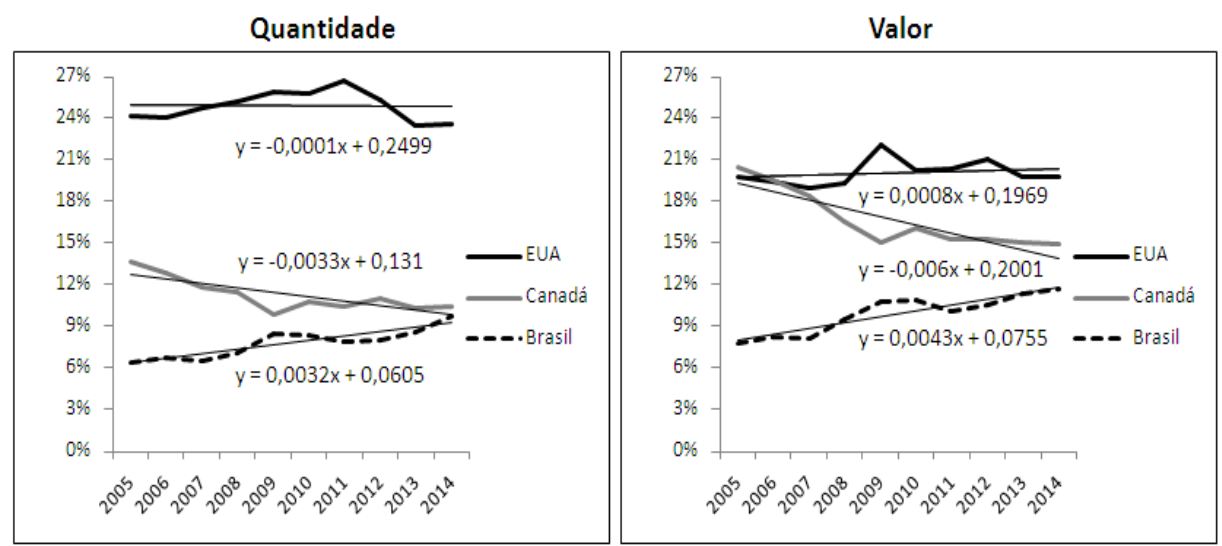

Gráfico 3. Participação relativa dos principais países exportadores de celulose

$\mathrm{Na}$ análise sob a ótica da quantidade o Brasil participava com 6,4\% do total das exportações no ano de 2005, passando a contribuir com 9,8\% em 2014. Ao analisar tendência por modelo linear estimado, tem-se que o coeficiente angular do modelo de quantidade para o Brasil apresentou inclinação positiva sugerindo aumento de market share no período. Diferentemente, para os EUA se pode 
perceber comportamento relativamente estável e para o Canadá nota-se queda de market share.

Em se tratando de valor das exportações, no período, a participação do Brasil passou de $7,8 \%$ para $11,7 \%$. Sob esta ótica, o modelo de tendência estimado para o Brasil também mostra-se com coeficiente angular positivo, sugerindo aumento médio de market share no período. Os EUA mostram certa estabilidade em termos de maket share e o Canadá evidenciou decrescimento médio de participação de mercado no período.

Esses resultados evidenciam um aumento da participação do Brasil nas exportações, no período, tanto em quantidade quanto em valor e, apesar do país se manter durante todo o período na terceira posição do ranking mundial, vem gradativamente se aproximando do volume de exportações canadenses e norte americanas. Apesar de ainda se ter informações parciais e não conclusivas referentes ao volume de exportações mundiais ocorridas em 2015, ceteris paribus, as tendências sugerem que o Brasil tenha minimante se aproximado muito do volume de celulose exportado pelo Canadá, com possibilidade de superação ainda no ano de 2015.

Dois importantes indicadores corroboram para o entendimento da contínua expansão da participação brasileira no mercado internacional, sendo estes: preço competitivo e expansão da oferta. O Brasil vem praticando, ao longo da série histórica, preços médios inferiores ao Canadá - Brasil (US\$ 479,16/ton.) e Canadá (US\$ 575,35/ton.) no ano de 2014 - até então o segundo maior exportador mundial, bem como de boa parte de outros países que são representativos no mercado internacional como Chile, Finlândia, Suécia, Indonésia e Rússia. Considerando que a prática de preços mais competitivos por parte do Brasil decorre de produção mais eficiente a custos menores de insumos (RADICCHI, 2004; MONTEBELLO, 2006; SOARES et al., 2010; MONTEBELLO; BACHA, 2013; SPEROTTO, 2014; BIAZUS; HORA; LEITE, 2016), este é um importante diferencial das empresas brasileiras no mercado internacional.

O segundo indicador da expansão contínua do Brasil no mercado global de celulose é a perspectiva, de curto e médio prazo, do aumento da capacidade produtiva (expansão da oferta).

Como exemplo, a Fibria, que opera com quatro fábricas no Brasil, tem 
capacidade instalada para 5,3 milhões de toneladas/ano de celulose de eucalipto e destaca-se como líder mundial na produção de celulose de fibra curta. A empresa está investindo na expansão da unidade de Três Lagoas (MS) e a nova linha de produção terá capacidade de 1,95 milhão de toneladas de celulose por ano. Com isso, a capacidade total de produção da Fibria passará dos atuais 5,3 milhões de toneladas de celulose/ano para mais de 7 milhões de toneladas de celulose/ano. A nova linha de produção está prevista para entrar em operação no quarto trimestre de 2017 (FIBRIA, 2016).

A empresa Suzano, segunda maior produtora de celulose de eucalipto do mundo, no final de 2013 iniciou suas atividades no Estado do Maranhão alcançando capacidade produtiva total de 3,4 milhões de toneladas/ano, contra os anteriores 1,9 milhões de toneladas/ano (SUZANO PAPEL E CELULOSE, 2016). Contudo, na área de celulose, a Suzano pretende expandir ainda mais sua capacidade anual de produção, almejando atingir 3,8 milhões de toneladas/ano, com investimentos estimados em R\$1,1 bilhão na fábrica de Imperatriz (Maranhão) e Mucuri (Bahia), até 2018 (FONTES, 2016).

A Eldorado Brasil tem capacidade instalada para 1,5 milhões de toneladas/ ano no município de Três Lagoas (MS). Com a conclusão de nova planta, denominada Projeto Vanguarda 2.0, prevista para o primeiro trimestre de 2019, alcançará uma produção de celulose próxima de 4 milhões de toneladas/ano (ELDORADO BRASIL, 2016). Já no Estado do Paraná, a empresa Klabin está dando andamento ao Projeto Puma, no município de Ortigueira. Com o início de operação, a Klabin amplia sua capacidade de produção em 1,5 milhões de toneladas de celulose/ano, sendo 1,1 milhão de celulose de fibra curta e 400 mil toneladas de celulose de fibra longa.

Há, porém, "barreiras" que impedem um desempenho ainda melhor do setor exportador brasileiro. Essas barreiras são entendidas pela Confederação Nacional da Indústria (2016) de maiores dificuldades enfrentadas pelas empresas brasileiras, sendo as de maior destaque: excesso de burocracia, sistema tributário brasileiro, infraestrutura de transporte, taxa de câmbio, barreiras tarifárias e não tarifárias, financiamento para exportação. Se atenuadas as referidas barreiras, poderse-ia estimular no país práticas crescentes de exportação, seja por empresas que já atuam no mercado internacional ou por empresas ingressantes.

\section{CONSIDERAÇÕES FINAIS}


Um processo de concentração de mercado está estreitamente relacionado com o avanço da competitividade das empresas, que buscam estratégias com intuito de conquistar, ou no mínimo manter, sua posição no mercado. Tais apontamentos vão de encontro com o enfoque da Escola de Chicago, porquanto o aumento na concentração e, portanto, à busca de economia de escala permitem não só a redução de custos como também ganhos de eficiência, culminando em maior rentabilidade.

Ao tratar de mercado internacional, há de se considerar também a autonomia das nações com relação às suas políticas macroeconômicas. No caso do Brasil, é importante ressaltar a política cambial, com excessiva desvalorização do câmbio, percebida a partir de 2012, como contributiva para melhor desempenho do setor no mercado internacional, nos últimos anos. A baixa ou nula intervenção no preço da divisa estrangeira, por parte do governo, via Banco Central, permitiu que as forças de mercado determinassem direcionamento e intensidade esperados pelo setor, repercutindo positivamente na participação de empresas brasileiras no mercado internacional.

Conclui-se que o mercado internacional de celulose classifica-se como baixa/ moderada concentração - $\mathrm{CR}(4), \mathrm{CR}(8)$-, altamente competitivo $(\mathrm{HH})$, não extremamente concentrado (B e E) e independentemente do tipo de análise (real ou monetária), bem como do indicador de concentração - CR(4), CR(8), HH, B e E - o período de 2005 a 2014 evidencia tendência de desconcentração do mercado.

Ressalva-se que o Brasil, apesar de se manter na terceira posição do ranking deste mercado durante todo o período analisado, vem gradativamente aumentando sua participação, com indícios de ter superado o volume exportado pelo Canadá, ainda em 2015, alcançando desta forma a posição de segundo maior exportador.

De toda forma as expectativas futuras são positivas para o setor no Brasil, devido aos fatores preço competitivo - o Brasil vem praticando preços médios inferiores ao Canadá e boa parte de outros países representativos no mercado internacional como Chile, Finlândia, Suécia, Indonésia e Rússia - e expansão da oferta - até 2019 as principais plantas industriais instaladas no Brasil planejam ampliar sua capacidade produtiva e juntas somam expectativa de ampliação superior a 6 milhões de toneladas/ano. 


\section{REFERÊNCIAS}

ALMEIDA, F. A.; SILVA, A. S. B. Índices de concentração: evidências empíricas à indústria de transformação cearense. In: ENCONTRO NACIONAL DE ENGENHARIA DE PRODUCAO, 35., 2015, Fortaleza. Anais [...]. Fortaleza: ENEGEP/ABEPRO, 2015.

AGRICULTURAL TECHNICAL COOPERATION WORKING GROUP. Market liberalization and its relationship with market structure, conduct and performance of the food processing industry in ASEAN economies. Malaysia: APEC/MARDI, 2008 .

BIAZUS, A.; HORA, A. B.; LEITE, B. G. P. Panorama de mercado: celulose. Disponível em: http://www.bndes.gov.br/SiteBNDES/export/sites/default/bndes_pt/Galerias/Arquivos/conhecimento/bnset/set32109.pdf. Acesso em: 25 set. 2016.

BRAGA, H. C.; MASCOLO, J. L. Mensuração da concentração industrial no Brasil. Pesquisa e Planejamento Econômico, Rio de Janeiro, v. 12, n. 2, p. 399-454, ago. 1982.

COELHO JÚNIOR, L. M.; REZENDE, J. L. P.; ÁVILA, E. S.; OLIVEIRA, A. D.; BORGES, L. A. C. Analysis of the brazilian cellulose industry concentration (1998-2007). Cerne, Lavras, v. 16, n. 2, p. 209-216, abr. / jun. 2010.

COELHO JÚNIOR, L. M.; REZENDE, J. L. P.; OLIVEIRA, A. D. Concentração das exportações mundiais de produtos florestais. Ciência Florestal, Santa Maria, v. 23, n. 4, p. 691-701, out./dez. 2013.

COMTRADE. Database. Disponível em: http://comtrade.un.org/db/dqBasicQuery. aspx. Acesso em: 18 jun. 2016.

CONFEDERAÇÃO NACIONAL DA INDÚSTRIA. As 10 maiores dificuldades enfrentadas pelas empresas brasileiras na hora de exportar. Disponível em: http://www.portaldaindustria.com.br/cni/. Acesso em: 10 nov. 2016.

PAULA, M. F. de. Desempenho das exportações brasileiras de mel natural. Universidade Federal do Paraná. 2014. 118 f. Tese (Doutorado em Engenharia Flores- 
tal) - Universidade Federal do Paraná, Curitiba, 2014.

ELDORADO DO BRASIL. Institucional. Disponível em: http://www.eldoradobrasil. com.br/Institucional. Acesso em: 26 set. 2016.

FIBRIA. O projeto. Disponível em: http://www.fibria.com.br/projetohorizonte2/o-projeto/sobre-o-projeto/ Acesso em: 26 set. 2016.

FONTES, S. Suzano aprova investimentos de $\mathbf{R} \$ \mathbf{1 , 6}$ bilhão até 2018. Disponível em: http://www.valor.com.br/empresas/4313106/suzano-aprova-investimentos-de-r-16-bilhao-ate-2018 Acesso em: 26 set. 2016.

FRIEDMAN, M. Capitalismo e liberdade. São Paulo: Abril Cultural, 1984. (Série "Os Economistas").

GALVÃO, R.; GOZER, I. C.; ORTIZ, G. F.; DAHMER, V. Concentração na agroindústria canavieira paranaense pós-desregulamentação setorial: uma análise aplicada de suas mesorregiões. In: CONGRESSO BRASILEIRO DE ECONOMIA E SOCIOLOGIA RURAL, 47., 2009, Porto Alegre. Anais [...]. Porto Alegre: SOBER/UFRGS, 2009.

GAMA, M. M.; RUIZ, R. M. A práxis antitruste no Brasil: uma análise do CADE no período entre 1994 e 2004. In: ENCONTRO NACIONAL DE ECONOMIA, 33., 2005, Natal. Anais [...]. Natal: ANPEC, 2005.

GEORGE, K. D.; JOLL, C.; LYNK, E. L. Industrial organization: competition, growth and structural change. London: Routledge, 1995.

HEIMANN, J. P.; DRESCH, A. R. Concentração das importações de carvão vegetal dos EUA e a participação brasileira. Rev. Acad., Ciênc. Agrár. Ambient., Curitiba, v. 11, supl. 1, p. S139-S146, 2013.

HOFFMANN, R. Distribuição de renda: medidas de desigualdade e pobreza. São Paulo: EDUSP, 1998.

INDÚSTRIA BRASILEIRA DA ÁRVORE. Anuário estatístico, 2015. Disponível em: http://iba.org/pt/. Acesso em: 18 abr. 2016. 
INDÚSTRIA BRASILEIRA DA ÁRVORE. Cenários IBÁ. IBÁ, n. 8, jan. 2015.

KALÇA, A.; ARI, V. O. Market concentration in turkish journalism sector. In: INTERNATIONAL CONFERENCE CHALLENGES OF THE KNOWLEDGE SOCIETY (CKS), 2013, Bucharest, Romania. Proceedings [...]. Bucharest: Nicolae Titulescu University of Bucharest, 2013. 884 p.

KAZEMZADEH, E.; ZEINODDIN, A. S. Sales concentration index in the iranian car market. Industrija, v. 43, n. 4, 2015.

KLABIN. Unidade Puma. Disponível em: https://www.klabin.com.br/pt/a-klabin/ unidade-puma/. Acesso em: 26 set. 2016.

KUPFER, D.; HASENCLEVER, L. (org.) Economia industrial. Rio de Janeiro: Campus, 2002. $640 \mathrm{p}$.

MONTEBELLO, A. E. S. Análise da evolução da indústria brasileira de celulose no período de 1980 a 2005. 2006. 115 f. Dissertação (Mestrado em Ciências) - Escola Superior de Agricultura Luiz de Queiroz, Universidade de São Paulo, Piracicaba, 2006.

LI, H.; MCCARTHY, P.; URMANBETOVA, A. Industry consolidation and price-cost margins: evidence from the pulp and paper industry. Atlanta: School of Economics, Georgia Institute of Technology, 2004.

LINDBLAD, F.; SCHAUERTE, T.; FLINKMAN, M. Changes in industry structure and concentration? Welfare loss due to perfect competition in the swedish industry for wooden singlefamily houses. FOREST PRODUCTS SOCIETY ANNUAL CONVENTION, 70., 2016, Portland. Proceedings [... ]. [Peachtree Corners]: Forest Products Society, 2016.

MATEOWS, N.; AMANUEL, T. W.; ASFAW, Z. Market chain analysis of agro-forestry products: the case of fruit at Tembaro District, Kembata Tembaro Zone South Ethiopia. International Journal of Business and Economics Research, v. 4, n. 4, p. 201-216, aug. 2015.

MEDEIROS, N. H.; OSTROSKI, D. A. Competitividade e concentração de mercado: 
uma análise da avicultura nas mesorregiões oeste e sudoeste paranaense. In: CONGRESSO DA SOCIEDADE BRASILEIRA DE ECONOMIA, ADMINISTRAÇÃO E SOCIOLOGIA RURAL, 44., 2006, Fortaleza. Anais [...]. Fortaleza: SOBER, 2006. p. 1-17.

MEDEIROS, N. H.; REIS, S. V. A concentração industrial na cadeia alimentar da soja. In: CONGRESSO DA SOCIEDADE BRASILEIRA DE ECONOMIA, ADMINISTRAÇÃO E SOCIOLOGIA RURAL, 37., 1999, Foz do Iguaçu. Anais [...]. Foz do Iguaçu: SOBER, 1999. p. $1-15$.

MONTEBELLO, A. E. S; BACHA, C. J. C. Impactos da reestruturação do setor de celulose e papel no Brasil sobre o desempenho de suas indústrias. Estudos Econômicos, São Paulo, v. 43, n. 1, p. 109-137, jan./mar. 2013.

MOSCHANDREAS, M. Business Economics. 2. ed. [s. 1]: Cengage Learning EMEA, 2005.

NOCE, R.; SILVA, M. L.; CARVALHO, R. M. M. A.; SOARES, T. S. Concentração das exportações no mercado internacional de madeira serrada. Revista Árvore, v. 29, n. 3, p. 431-437, 2005.

RADICCHI, C. C. Competitividade das exportações brasileiras de celulose: uma análise do custo Brasil. 2004. 83 f. Dissertação (Mestrado em Economia Aplicada) - Universidade Federal de Viçosa, Viçosa, 2004.

RESENDE, M. Medidas de concentração industrial: uma resenha. Análise Econômica, ano 11, p. 24-33, mar./set. 1994.

RESENDE, M.; BOFF, H. Concentração industrial. In: KUPFER, D.; HASENCLEVER, L. (org.). Economia industrial. Rio de Janeiro: Campus, 2002.

RIBEIRO, O. F. R.; TONIN, J. M. Análise da concorrência bancária no Brasil pós Plano Real. Textos de Economia, v. 13, n. 2, p. 59-86, jul./dez. 2010.

ROCHA, A. P. A.; SOARES, N. S. Desempenho das exportações brasileiras do setor de papel e celulose, entre 1997 e 2011. Informações Econômicas, São Paulo, v. 44, n. 6, p. 5-15, nov./dez. 2014. 
RUGAYAH, M. Market structure and structure-conduct-performance paradigm: empirical evidence from developing. Malaysian Journal of Economic Studies, v. 30, n. 1, p. 55-76, 1993.

SERVIÇO FLORESTAL BRASILEIRO. Informações florestais. Disponível em: http:// www.florestal.gov.br/snif/. Acesso em: 9 nov. 2016.

SILVA, Z. A. G. P. G. Análise da concentração no uso de madeira tropical pelo setor de marcenarias de Rio Branco, Estado do Acre, 1996. Scientia Forestalis, n. 64, p. 48-58, 2003.

SOARES, N. S.; OLIVEIRA, R. J.; CARVALHO, K. H. A.; SILVA, M. L. S.; JACOVINE, A. G.; VALVERDE, S. R. A cadeia produtiva da celulose e do papel no Brasil. Floresta, Curitiba, v. 40, n. 1, p. 1-22, jan./mar. 2010.

SPEROTTO, F. Q. A expansão do setor de celulose de mercado no Brasil: condicionantes e perspectivas. Indicadores Econômicos FEE, Porto Alegre, v. 41, n. 4, p. 85-100, 2014.

STIGLER, G. The organization of industry. Chicago: Universith of Chicago Press, 1968.

SUZANO PAPEL E CELULOSE. Quem somos. Disponível em: http://www.suzano. com.br/portal/suzano-papel-e-celulose/quem-somos.htm. Acesso em: 22 ago. 2016.

THEIL, H. Economics and information theory. Amsterdam: North-Holland, 1967. $488 \mathrm{p}$.

TUSHAJ, A. Market concentration in the banking sector: evidence from Albania. Working Paper Series on Government and Growth, n. 73, apr. 2010.

VALVERDE, S. R.; SOARES, N. S.; SILVA, M. L. Desempenho das exportações brasileiras de celulose. Revista Árvore, Viçosa, v. 30, n. 6, p. 1017-1023, 2006.

VIAN, C. E. de F.; LIMA, R. A. de S.; LIMA, A. A. Estudo de impacto econômico (eis) para o setor agroindustrial canavieiro paulista e alagoano: conjuntura e agenda de pesquisa. In: CONGRESSO BRASILEIRO DE ECONOMIA E SOCIOLOGIA RURAL, 
44., 2006, Fortaleza. Anais [...]. Fortaleza: SOBER/UFC, 2006.

Recebido em: 14/08/2017

Aceito em: 07/02/2019 